\title{
Comprehensive Evaluation for Teaching Quality of College Faculty
}

\author{
https://doi.org/10.3991/ijet.v16i18.25663 \\ Nan Xia, Yanan Yang $(\bowtie)$ \\ Chengde Medical University, Chengde, China \\ xyang0 $5281 @ 163$. com
}

\begin{abstract}
The fair, objective, scientific, and comprehensive evaluation of teaching quality helps college teachers improve the quality of teaching, and enables colleges to realize their goals of talent training. Therefore, it is important to find a way to comprehensively evaluate the teaching quality of college teachers. Drawing on the theories of analytic hierarchy process (AHP), this paper sets up an evaluation index system (EIS) for teaching quality of college teachers, and determines the weight of each index. Taking the teachers of a college for example, the multi-level fuzzy comprehensive evaluation (FCE) was carried out to quantify the teaching quality of these teachers. The results show that AHP and FCE can quantify and qualify the teaching quality at the same time. The combined use of the two techniques is applicable to comprehensive evaluation of teaching quality, and the assessment of a single factor, offering a complete understanding of the teaching quality of college teachers. The research provides a scientific way to evaluate the teaching quality of college teachers, and a realistic tool to enhance the teaching quality in colleges.
\end{abstract}

Keywords - analytic hierarchy process (AHP), fuzzy comprehensive evaluation (FCE), teacher, teaching quality evaluation

\section{Introduction}

In China, although the popularization of higher education has satisfied people's strong desire and ardent demand for higher education, in recent years, as the scale of higher education expands gradually, the teaching quality of higher education has been questioned by the public, in view of this issue, Chinese government has now included the improvement of teaching quality of higher education in the top agenda, and this issue has become the core task of the development of higher education. Under normal conditions, teachers, student sources, and school resources are regarded as three main factors that can affect the quality of teaching; teachers are the executors of teaching tasks; therefore, they are the key influencing factor of teaching quality of higher education [1]. The evaluation of the classroom teaching quality of college faculty is an important link in the teaching quality management of colleges and universities, it has very important significance for improving the teaching quality of the faculty and 
efficiency of the school, as a result, quite a few scholars have conducted research on the comprehensive evaluation of the teaching quality of college faculty.

Teaching assessment has become a separate discipline since the end of the 19th century, and it develops and improves continuously along with the development of education [2]. The United States and the United Kingdom have respectively formulated standards for teacher assessment. The NBPTS standards formulated by the United States consist of five parts, and the British teacher assessment standards consist of two parts: teaching practice and teaching effect [3]. In China, although the research on the teaching quality evaluation of college teachers is quite common already and teaching assessment has been carried out in most schools, these assessment methods are traditional means such as distributing scoring tables and asking students and experts to score, and then taking the average scores as the final assessment results [4]. However, existing teaching quality EISs are flawed, assessment methods are rigescent, the quantitative analysis of the weights of evaluation indexes lacks evidence, the weight values are usually determined by a few experts based on their personal experience, the so-called "quantified" evaluation results make the objectivity and completeness of the evaluation questionable, and it's difficult to give fair assessment to the teaching quality of teachers, which can harm the improvement of teachers' teaching ability [5]. AHP and FCE are two techniques commonly used in teaching quality evaluation at home and abroad, both have their respective pros and cons [6].

In order to get more objective and accurate faculty teaching quality evaluation results, this study proposes to combine AHP with FCE to build EIS, determine index weights, and give comprehensive assessments to the teaching quality of college faculty.

\section{Methodology}

\section{$2.1 \quad$ About AHP}

AHP is a systematic analysis method that integrates quantitative analysis and qualitative analysis, it is applicable to determining the weight coefficients of indexes in complex problems, the method has many merits, it's systematic, simple, easy to understand, flexible, and practical [7]. The basic process is shown in Figure 1 [8].

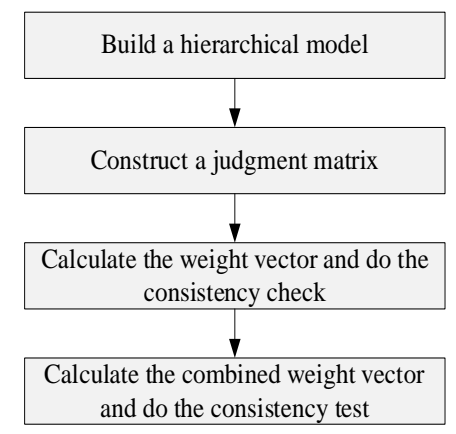

Fig. 1. Flow of AHP 


\subsection{About FCE}

Many indexes are involved in the teaching quality evaluation of college faculty, however, some of them are fuzzy and have no clear boundaries or specific extensions, and they cannot be expressed as a definite number [9]. The FCE is an accurate evaluation method for fuzzy things developed based on the basic principles of fuzzy mathematics [10]. From bottom level to top level, the multi-level FCE gives comprehensive evaluations on each category of indexes level by level, and finally gets the comprehensive evaluation results [11]. This method can avoid the inaccuracy problem of fuzzy calculation when there are too many evaluation indexes. Figure 2 gives the steps of multi-level FCE [12].

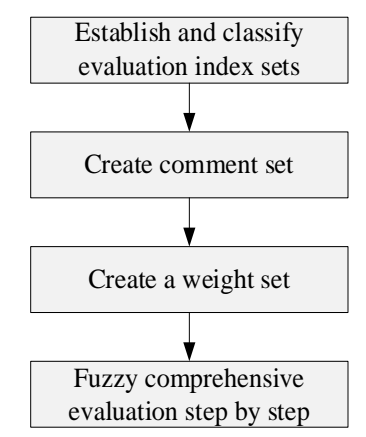

Fig. 2. Steps of multi-level FCE

\section{Construction of EIS}

\subsection{Evaluation index analysis}

In order to give scientific and objective evaluations, the first thing to do is to determine the evaluation indexes and their specific content, after reviewing relevant literatures, this study compared, analyzed, and summarized similar EISs in recent years, and decided to analyze the evaluation indexes and their content from four aspects, see Figure 3 [13].

1. Teaching content: Teaching content is the fundamental point for teaching quality evaluation, and the quality of teaching content directly affects the quality of teaching. Generally, the teaching content-related indexes should contain the following content: whether the teaching content is in line with the teaching goals of professional courses; whether the teaching content is clear, comprehensive, correct, and systematic; whether the teaching content can combine knowledge with specific ability [14]. 


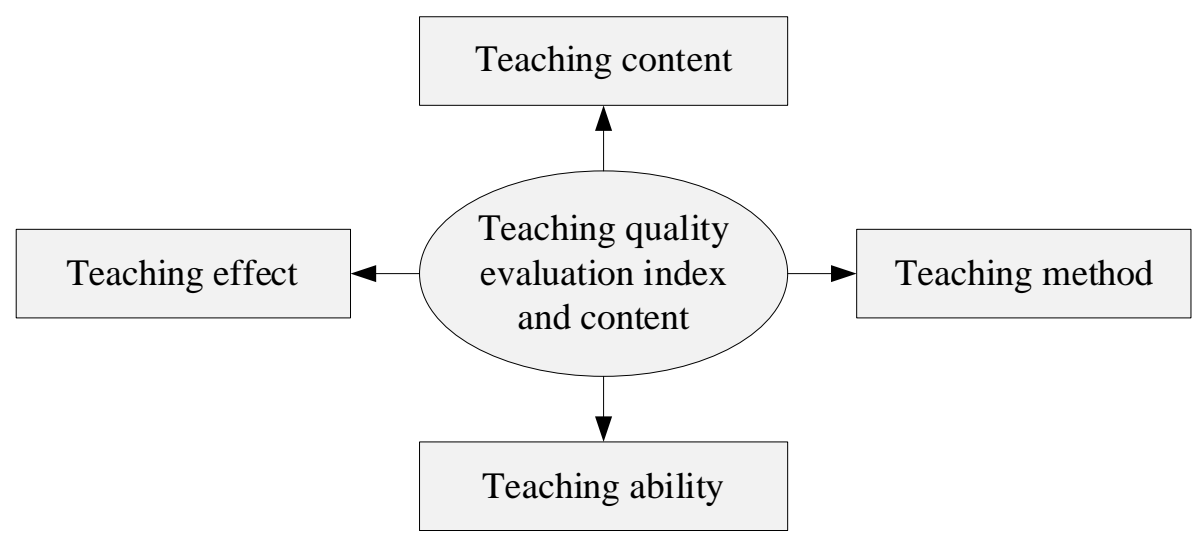

Fig. 3. Teaching quality evaluation indexes and their content

2. Teaching method: Teaching methods are the specific means and ways applied by teachers during the teaching process to achieve the teaching goals and ensure the imparting of teaching content, with the gradual advancement of education and teaching reforms, the traditional teaching methods can no longer meet the needs of modern quality education. Teachers should adopt diverse teaching methods and tools based on actual situations of teaching goals, teaching content, and students, and try their best to trigger students' learning enthusiasm and cultivate their various abilities and qualities. When evaluating the teaching methods, there is a saying: there're fixed rules in teaching, but the teaching methods shouldn't be fixed, therefore, the evaluation indexes related to teaching method should contain the following content: whether the teaching method is diverse and flexible; and whether the teaching method can meet the actual requirements of students and teaching [15].

3. Teaching ability: Teachers' teaching ability mainly includes: general ability, lecturing ability, academic research ability, and teaching research ability. Solely from the perspective of classroom teaching quality, teachers' teaching ability should include: the ability to master professional knowledge, the ability to practice, the basic professional skills (such as language expression ability and textbook explanation ability), the ability to understand and inspire students, the ability to organize and manage the classrooms, and the ability to apply teaching methods, etc. [16].

4. Teaching effect: Teaching effect is the result of teaching. Generally, it should include the following content: the completion of teaching goals; students' ability, attitude, and emotional goals realization; the classroom teaching atmosphere; and student participation.

\subsection{Determination of the subjects of teaching quality evaluation}

In order to build a college faculty teaching quality evaluation system with full participation and benign interaction and improve the reliability and validity of teaching quality evaluation, it's necessary to build the evaluation system with multiple evaluation subjects. 
1. Student evaluation is primary: Students are main participants, objects, and knowledge receivers in the teaching activities, so they have the most say in teaching quality evaluation. College students have mature minds, independent thinking, and correct judgement, therefore, they can give objective and accurate evaluations on the teaching quality of teachers. Students' evaluation is helpful for teachers to discover problems existing the teaching process in a timely manner, thus optimizing the teaching activities and improving the teaching quality. In the evaluation of college faculty teaching quality, it's very necessary to determine the primary status of students [17].

2. Expert evaluation is guarantee: Most colleges and universities have introduced peer evaluation and expert evaluation in teaching quality evaluation, however, due to the influence of human relationships, peer evaluation results are easily distorted. In terms of expert evaluation, professional experts who are experienced in teaching and familiar with classroom teaching activities are invited by colleges and universities to form supervisor teams and they are asked to attend 1-2 lectures randomly each semester, however, since there're many accidental factors in this lecture supervision mode, still the evaluation results might be one-sided. In order to avoid these unwanted situations and ensure that the evaluation results are objective, fair, accurate and effective, this study randomly selected a peer and a supervisor to form an expert evaluation team, the two team members were asked to score the teaching quality of a same teacher at different times, if the difference between the two scores is too large, then the evaluation is considered invalid; if the difference is not large, then the average score is taken as the final expert evaluation result [18].

3. Teacher self-evaluation is foundation: Teachers are the designers, organizers, and implementers of teaching activities. Only the teachers themselves know the extent of their efforts, the progress made by students, and the degree of realization of the teaching goals best. Self-evaluation is helpful for teachers to timely reflect on the teaching activities, discover problems in teaching works, adjust the teaching works, and improve their professional level constantly, therefore, teacher self-evaluation is a fundamental impetus for improving teaching quality [19].

\subsection{EIS for college faculty teaching quality}

Based on the analysis in above paragraphs concerning the evaluation indexes, content, and evaluation subjects, this paper constructed an EIS for college faculty teaching quality, as shown in Figure 4. 
Paper-Comprehensive Evaluation for Teaching Quality of College Faculty

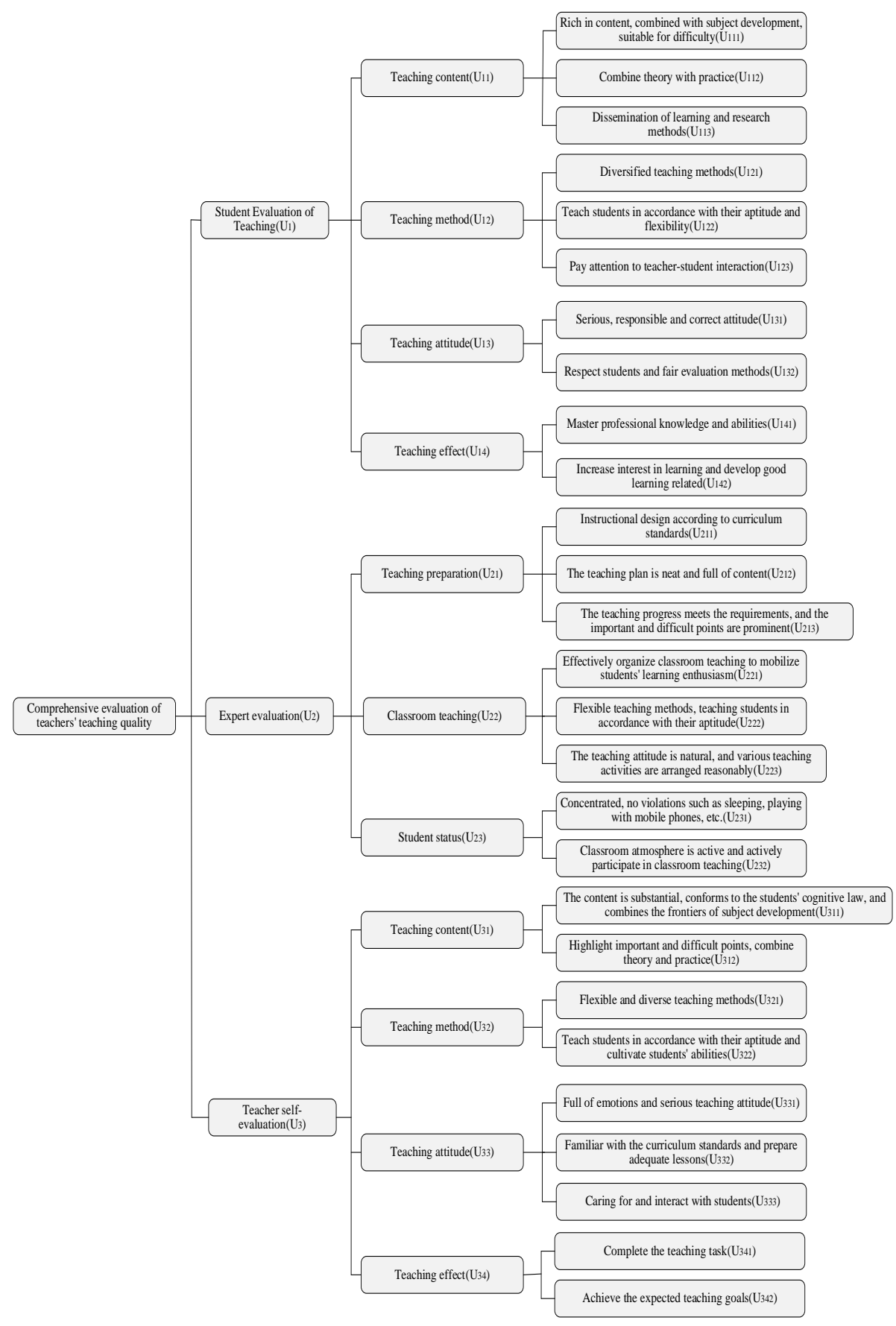

Fig. 4. Structure of the proposed EIS 


\section{Teaching quality FCE}

\subsection{Index weight determination}

The weight values of indexes in each level were determined by AHP. To ensure reasonable weight value distribution of evaluation indexes, 10 experienced experts from several colleges were invited to construct judgement matrixes using 1-9 scales, numbers $1,3,5,7$, and 9 represent that in the matrix $A_{i}$ is equally important to, slightly more important than, more important than, much more important than, and extremely more important than $A_{j}$; and numbers $2,4,6$, and 8 represent and the degree of importance is between two adjacent degrees, for example, 2 represents the degree of importance is between equally important and slightly more important [20].

Table 1. Weight values of teaching quality evaluation indexes

\begin{tabular}{|c|c|c|c|c|}
\hline Evaluation subject & First-level index & Weight & Second-level index & Weight \\
\hline \multirow{10}{*}{ U1 } & \multirow{3}{*}{ U11 } & \multirow{3}{*}{0.474} & U111 & 0.218 \\
\hline & & & U112 & 0.497 \\
\hline & & & U113 & 0.285 \\
\hline & \multirow{3}{*}{$\mathrm{U} 12$} & \multirow{3}{*}{0.207} & U121 & 0.463 \\
\hline & & & U122 & 0.296 \\
\hline & & & U123 & 0.241 \\
\hline & \multirow{2}{*}{ U13 } & \multirow{2}{*}{0.112} & U131 & 0.521 \\
\hline & & & U132 & 0.479 \\
\hline & \multirow{2}{*}{ U14 } & \multirow{2}{*}{0.207} & U141 & 0.500 \\
\hline & & & U142 & 0.500 \\
\hline \multirow{8}{*}{$\mathrm{U} 2$} & \multirow{3}{*}{$\mathrm{U} 21$} & \multirow{3}{*}{0.194} & $\mathrm{U} 211$ & 0.267 \\
\hline & & & $\mathrm{U} 212$ & 0.367 \\
\hline & & & $\mathrm{U} 213$ & 0.366 \\
\hline & \multirow{3}{*}{$\mathrm{U} 22$} & \multirow{3}{*}{0.545} & $\mathrm{U} 221$ & 0.237 \\
\hline & & & $\mathrm{U} 222$ & 0.627 \\
\hline & & & U223 & 0.136 \\
\hline & \multirow{2}{*}{$\mathrm{U} 23$} & \multirow{2}{*}{0.261} & U231 & 0.355 \\
\hline & & & $\mathrm{U} 232$ & 0.645 \\
\hline \multirow{9}{*}{ U3 } & \multirow{2}{*}{ U31 } & \multirow{2}{*}{0.166} & U311 & 0.532 \\
\hline & & & U312 & 0.468 \\
\hline & \multirow{2}{*}{$\mathrm{U} 32$} & \multirow{2}{*}{0.331} & U321 & 0.411 \\
\hline & & & U322 & 0.589 \\
\hline & \multirow{3}{*}{ U33 } & \multirow{3}{*}{0.215} & U331 & 0.473 \\
\hline & & & U331 & 0.254 \\
\hline & & & U331 & 0.273 \\
\hline & \multirow{2}{*}{ U34 } & \multirow{2}{*}{0.288} & U341 & 0.342 \\
\hline & & & U342 & 0.658 \\
\hline
\end{tabular}


Taking the teaching content in the student evaluation indexes as an example, a judgment matrix U11 was constructed by the experts as:

$$
U_{11}=\left[\begin{array}{ccc}
1 & 1 / 2 & 2 / 3 \\
2 & 1 & 2 \\
3 / 2 & 1 / 2 & 1
\end{array}\right]
$$

The matrix was normalized to obtain $\overline{U_{11}}$ :

$$
\overline{U_{11}}=\left[\begin{array}{ccc}
0.222 & 0.25 & 0.182 \\
0.444 & 0.5 & 0.545 \\
0.333 & 0.25 & 0.273
\end{array}\right]
$$

Rows in $\overline{U_{11}}$ were added to obtain $\overline{W_{11}}$ :

$$
\overline{W_{11}}=\left[\begin{array}{l}
0.654 \\
1.490 \\
0.856
\end{array}\right]
$$

$\overline{W_{11}}$ was normalized:

$$
W_{11}=\left[\begin{array}{l}
0.218 \\
0.497 \\
0.285
\end{array}\right]
$$

Calculate $\lambda_{\max }$ :

$$
\lambda_{\max }=\frac{1}{n} \sum_{i=1}^{n}\left[\frac{\sum_{j=1}^{n} a_{i j} w_{i j}}{w_{j}}\right]
$$

$\lambda_{\max }$ is the maximum eigenvalue of the judgment matrix.

Then the maximum value of the eigenvector of the teaching content matrix in the student evaluation indexes is $\lambda$ max .

$$
\begin{aligned}
& \lambda_{\max }=\frac{1}{n} \sum_{i=1}^{n}\left[\frac{\sum_{j=1}^{n} a_{i j} w_{i j}}{w_{j}}\right] \\
& =\frac{1}{3}\left(\frac{1 \times 0.218+1 / 2 \times 0.497+2 / 3 \times 0.285}{0.218}+\frac{2 \times 0.218+1 \times 0.497+2 \times 0.285}{0.497}+\frac{3 / 2 \times 0.218+1 / 2 \times 0.497+1 \times 0.285}{0.285}\right) \\
& =3.018
\end{aligned}
$$


Perform consistency check:

$$
\begin{aligned}
& C I=\frac{\lambda \max -n}{n-1}=\frac{3.018-3}{3-1}=0.009 \\
& C R=\frac{C I}{R I}
\end{aligned}
$$

where, $R I$ is random index, by looking up tables it's known that when $\mathrm{n}=3$, $R I=0.58$, and $C R=\frac{C I}{R I}=\frac{0.009}{0.58}=0.016<0.1$, the result passed the consistency check, indicating that the weight distribution was reasonable, and $W_{11}=(0.218,0.497,0.285)$

For indexes of each level, the calculation method is the same, Table 1 lists the calculated weight values of evaluation indexes.

\subsection{FCE of teaching quality}

\section{FCE of student evaluation}

1. Establish evaluation sets: The second-level evaluation index sets of student evaluation were established as:

$$
U_{11}=\left(U_{111}, U_{112}, U_{113}\right), U_{12}=\left(U_{121}, U_{122}, U_{123}\right), U_{13}=\left(U_{131}, U_{132}\right), \quad U_{14}=\left(U_{141}, U_{142}\right)
$$

2. Establish comment set: Since teachers with different education degrees, work experience, and professional titles have different teaching levels, this paper referred to expert opinions and divided the evaluation results of college faculty teaching quality into four levels: excellent, good, average, and need to be improved, and then a comment set was established accordingly:

$V=\left\{V_{1}, V_{2}, V_{3}, V_{4}\right\}=\{$ excellent, good, medium, It needs to be strengthened $\}$.

3. Establish weight sets According to above calculation results, weight sets of student evaluation indexes were established:

$$
\begin{aligned}
W_{11} & =\{0.218,0.497,0.285\} \\
W_{14} & =\{0.500,0.500\}
\end{aligned}, \quad W_{12}=\{0.463,0.296,0.241\} \quad W_{13}=\{0.521,0.497\}
$$

4. Establish the judgement matrix of membership degree

$$
R_{i}=\left\{r_{i 1}, r_{i 2} \cdots, r_{i m}\right\}
$$

$r_{i j}=\frac{\text { The number of people who choose level vi for the } \mathrm{i} \text { index }}{\text { The total number of people participating in the evaluation }}$

300 students from a university were invited to evaluate the teaching quality of a teacher X, after the results were sorted out and analyzed, judgement matrixes of 
membership degree of teaching content, teaching method, teaching attitude and teaching effect were constructed, here the judgement matrix of membership degree of teaching content is taken as an example for calculation and analysis.

The evaluation matrix of membership degree of teaching content is:

$$
R_{11}=\left[\begin{array}{cccc}
0.21 & 0.64 & 0.12 & 0.03 \\
0.26 & 0.62 & 0.12 & 0 \\
0.11 & 0.33 & 0.32 & 0.24
\end{array}\right]
$$

\section{Secondary FCE}

The teaching content was subject to secondary FCE:

$$
\begin{aligned}
S_{11}^{\prime} & =W_{11} \times R_{11}=\{0.218,0.497,0.285\} \times\left[\begin{array}{cccc}
0.21 & 0.64 & 0.12 & 0.03 \\
0.26 & 0.62 & 0.12 & 0 \\
0.11 & 0.33 & 0.32 & 0.24
\end{array}\right] \\
& =\{0.2064,0.5417,0.1770,0.0749\}
\end{aligned}
$$

$S_{11}^{\prime}$ was normalized to get: $S_{11}=\{0.2593,0.6466,0.1819,0.0041\}$

The same calculation method was adopted to obtain the evaluation value of the membership degree of teaching method:

$S_{12}=\{0.3045,0.3913,0.2824,0.0218\}$

The evaluation value of the membership degree of teaching attitude is:

$S_{13}=\{0.5443,0.2654,0.1790,0.0113\}$

The evaluation value of the membership degree of teaching effect is:

$S_{14}=\{0.4543,0.3266,0.2157,0.0034\}$

6. Primary FCE: Establish primary fuzzy comprehensive matrix of student evaluation:

$$
R_{1}=\left[\begin{array}{l}
S_{11} \\
S_{12} \\
S_{13} \\
S_{14}
\end{array}\right]=\left[\begin{array}{llll}
0.2593 & 0.6466 & 0.1819 & 0.0041 \\
0.3045 & 0.3913 & 0.2824 & 0.0218 \\
0.5443 & 0.2654 & 0.1790 & 0.0113 \\
0.4543 & 0.3266 & 0.2157 & 0.0034
\end{array}\right]
$$

Perform primary FCE:

$W_{1}=\{0.474,0.207,0.112,0.207\}$ 


$$
\begin{aligned}
S_{1}^{\prime} & =W_{1 \times} R_{1}=\{0.474,0.207,0.112,0.207\} \times\left[\begin{array}{cccc}
0.2593 & 0.6466 & 0.1819 & 0.0041 \\
0.3045 & 0.3913 & 0.2824 & 0.0218 \\
0.5443 & 0.2654 & 0.1790 & 0.0113 \\
0.4543 & 0.3266 & 0.2157 & 0.0034
\end{array}\right] \\
& =\{0.3406,0.4839,0.2168,0.0084\}
\end{aligned}
$$

After normalization, the vector of primary FCE of student evaluation was obtained:

$$
S_{1}=\{0.0465,0.6507,0.2915,0.0113\}
$$

FCE of expert evaluation. Using the same calculation method, the evaluation values of the membership degree of secondary FCE of expert evaluation and teacher selfevaluation were obtained:

Teaching preparation: $S_{21}=\{0.2453,0.4321,0.3102,0.0124\}$

Classroom lecturing: $S_{22}=\{0.5532,0.3174,0.1235,0.0059\}$

Student status: $S_{23}=\{0.4572,0.3428,0.1978,0.0042\}$

Perform primary FCE:

$$
\begin{aligned}
& W_{2}=\{0.194,0.545,0.261\} \\
& S_{2}{ }_{2}=W_{2 \times} R_{2}=\{0.194,0.545,0.261\} \times\left[\begin{array}{llll}
0.2453 & 0.4321 & 0.3102 & 0.0124 \\
0.5532 & 0.3174 & 0.1235 & 0.0059 \\
0.4572 & 0.3428 & 0.1978 & 0.0042
\end{array}\right] \\
&=\{0.3640,0.4003,0.3766,0.3189\}
\end{aligned}
$$

After normalization, the vector of primary FCE of expert evaluation was obtained: $S_{2}=\{0.2493,0.2742,0.2580,0.2185\}$

FCE of teacher self-evaluation. In the same way, the evaluation values of the membership degree of secondary FCE of teacher self-evaluation were obtained as:

Teaching content: $S_{31}=\{0.2543,0.3015,0.3468,0.0974\}$

Teaching method: $S_{32}=\{0.3145,0.3596,0.2016,0.1243\}$

Teaching attitude: $S_{33}=\{0.2987,0.4252,0.2118,0.0643\}$

Teaching effect: $S_{34}=\{0.1984,0.2138,0.3443,0.2435\}$ 
Perform primary FCE:

$W_{3}=\{0.166,0.331,0.215,0.288\}$

$S_{3}^{\prime}=W_{3 \times} R_{3}=\{0.166,0.331,0.215,0.288\} \times\left[\begin{array}{cccc}0.2543 & 0.3015 & 0.3468 & 0.0974 \\ 0.3145 & 0.3596 & 0.2016 & 0.1243 \\ 0.2987 & 0.4252 & 0.2118 & 0.0643 \\ 0.1984 & 0.2138 & 0.3443 & 0.2435\end{array}\right]$

$=\{0.2677,0.3221,0.2719,0.1413\}$

After normalization, the vector of primary FCE of teacher self-evaluation was obtained: $S_{3}=\{0.2669,0.3211,0.2711,0.1409\}$

\subsection{FCE of teaching quality}

Experts and teachers with rich teaching and management experience were selected and actual conditions of the colleges and universities were combined to determine the evaluation weights of student evaluation, expert evaluation, and teacher selfevaluation as $W=\{0.5,0.3,0.2\}$. The FCE matrix established based on each evaluation subject is:

$$
R=\left\{\begin{array}{l}
S_{1} \\
S_{2} \\
S_{3}
\end{array}\right\}=\left[\begin{array}{llll}
0.0465 & 0.6507 & 0.2915 & 0.0113 \\
0.2493 & 0.2742 & 0.2580 & 0.2185 \\
0.2669 & 0.3211 & 0.2711 & 0.1409
\end{array}\right]
$$

The FCE vector is:

$$
\begin{aligned}
S & =W \times R=\{0.5,0.3,0.2\} \times\left[\begin{array}{llll}
0.0465 & 0.6507 & 0.2915 & 0.0113 \\
0.2493 & 0.2742 & 0.2580 & 0.2185 \\
0.2669 & 0.3211 & 0.2711 & 0.1409
\end{array}\right] \\
& =\{0.1649,0.4718,0.2774,0.0994\}
\end{aligned}
$$

In order to quantify the teaching quality of teachers and get the evaluation scores, values were assigned to the comment set as:

$$
\begin{aligned}
V= & \left\{V_{1}, V_{2}, V_{3}, V_{4}\right\}=\{\text { excellent, good, medium, It needs to be strengthened }\} \\
& =\{95,85,75,65\}
\end{aligned}
$$

The final evaluation score of the teaching quality of teacher $\mathrm{X}$ is: 


$$
A=S \times V^{T}=\{0.1649,0.4718,0.2774,0.0994\} \times\left\{\begin{array}{c}
95 \\
85 \\
75 \\
65
\end{array}\right\}=83.0345
$$

According to the FCE results, the teaching level of this teacher is higher than the average level, and is close to the good level.

\section{Conclusions}

The teaching quality evaluation of college faculty is a multi-index comprehensive evaluation process. This study integrated AHP and FCE to research the comprehensive evaluation methods of college faculty teaching quality, and obtained following conclusions:

1. This paper analyzed the evaluation indexes, the index content, and the evaluation subjects of college faculty teaching quality, and pointed out that the evaluation indexes should include four aspects of teaching content, teaching method, teaching attitude, and teaching effect; the evaluation should take student evaluation as primary, expert evaluation as guarantee, and teacher self-evaluation as foundation.

2. This paper proposed a new EIS for college faculty teaching quality, and used AHP to determine the weights of each index.

3. Taking a teacher $X$ in a university as an example, this paper adopted multi-level FCE to score teacher X's indexes, and obtained the final evaluation score of this teacher after quantification. By combining qualitative analysis and quantitative analysis, this paper overcome the subjectivity and arbitrariness of traditional teaching quality evaluation, and accurately and comprehensively evaluated the teaching quality of teachers.

\section{Acknowledgment}

1. Chengde Medical College's 2019 school-level project, a study on the Chinese outlook and Chinese cultural influence of international students from universities in Hebei Province, Number: 201909.

2. 2020 Hebei Province Social Science Development Research Project, Research on the Path to Improve the National Cultural Soft Power and Chinese Cultural Influence-Taking the Education of International Students in Hebei Province as an Example, No.: 20200603119. 


\section{$7 \quad$ References}

[1] Yang, J., Shen, L., Jin, X., Hou, L., Shang, S., Zhang, Y. (2019). Evaluating the quality of simulation teaching in Fundamental Nursing Curriculum: AHP-Fuzzy comprehensive evaluation. Nurse education today, 77: 77-82. https://doi.org/10.1016/j.nedt.2019.03.012

[2] Allard, A.C., Mayer, D., Moss, J. (2014). Authentically assessing graduate teaching: Outside and beyond neo-liberal constructs. The Australian Educational Researcher, 41(4): 425-443. https://doi.org/10.1007/s13384-013-0140-x

[3] Xie, Z., Su, Z. (2021). Evaluation of college English classroom teaching quality dependent on triangular fuzzy number. The International Journal of Electrical Engineering \& Education, 0207209211002075. https://doi.org/10.1177/00207209211002075

[4] Hu, Y., Li, N., Luo, C. (2020). Quality evaluation of practical training of innovative and entrepreneurial talents in universities based on statistical learning theory after COVID-19 epidemic. Journal of Intelligent \& Fuzzy Systems, (Preprint), 1-7. https://doi.org/ $\underline{10.3233 / \text { jifs- } 189303}$

[5] Parpala, A., Lindblom-Ylänne, S. (2007). University Teachers'Conceptions of Good Teaching in The Units of High-Quality Education. Studies in Educational Evaluation, 33(3-4): 355-370. https://doi.org/10.1016/j.stueduc.2007.07.009

[6] Zhu, W., Wan, M., Zhou, Y., Pan, W. (2018). Fuzzy computation of teaching performance based on data envelopment analysis method. Cognitive Systems Research, 52 351-358. https://doi.org/10.1016/j.cogsys.2018.07.018

[7] De Witte, K., Rogge, N., Cherchye, L., Van Puyenbroeck, T. (2013). Accounting for economies of scope in performance evaluations of university professors. Journal of the Operational Research Society, 64(11): 1595-1606. https://doi.org/10.1057/jors.2012.115

[8] Huang, W.M. (2021). Simulation of english teaching quality evaluation model based on gaussian process machine learning. Journal of Intelligent and Fuzzy Systems, 40(2): 23732383. https://doi.org/10.3233/jifs-189233

[9] Sun, Q.N. (2021). Evaluation model of classroom teaching quality based on improved RVM algorithm and knowledge recommendation. Journal of Intelligent \& Fuzzy Systems, (Preprint), 40(2): 2457-2467. https://doi.org/10.3233/jifs-189240

[10] Sidorkin, A. (2013). Professional teacher training in the us: lessons for russia. Voprosy Obrazovaniya/ Educational Studies Moscow, 1(1): 136-155. https://doi.org/10.17323 1814-9545-2013-1-136-155

[11] Peng, X., Dai, J. (2019). Research on the assessment of classroom teaching quality with qrung orthopair fuzzy information based on multiparametric similarity measure and combinative distance-based assessment. International Journal of Intelligent Systems, 34(7): 1588-1630. https://doi.org/10.1002/int.22109

[12] Yu, D. (2013). Prioritized information fusion method for triangular intuitionistic fuzzy set and its application to teaching quality evaluation. International Journal of Intelligent Systems, 28(5): 411-435. https://doi.org/10.1002/int.21583

[13] Brito, R.M., Rodríguez, C., Aparicio, J.L. (2018). Sustainability in teaching: An evaluation of university teachers and students. Sustainability, 10(2): 439. https://doi.org/10.3390 /su10020439

[14] Liu, S. (2021). Research on the teaching quality evaluation of physical education with intuitionistic fuzzy TOPSIS method. Journal of Intelligent \& Fuzzy Systems, (Preprint), 110. https://doi.org/10.3233/jifs-201672

[15] Warman, S.M. (2015). Challenges and issues in the evaluation of teaching quality: How does it affect teachers' professional practice? a UK perspective. Journal of veterinary medical education, 42(3): 245-251. https://doi.org/10.3138/jvme.0914-096r1 
[16] Lock, A., Berry, T., Easterby-Smith, M. (1998). Judging Teaching Quality: the assessment of teaching quality in UK business and management schools. Management Learning, 29(4): 485-499. https://doi.org/10.1177/1350507698294006

[17] Lander, N.J., Barnett, L.M., Brown, H., Telford, A. (2015). Physical education teacher training in fundamental movement skills makes a difference to instruction and assessment practices. Journal of Teaching in Physical Education, 34(3): 548-556. https://doi.org/10. 1123/itpe.2014-0043

[18] Yang, J., Shen, L., Jin, X., Hou, L., Shang, S., Zhang, Y. (2019). Evaluating the quality of simulation teaching in Fundamental Nursing Curriculum: AHP-Fuzzy comprehensive evaluation. Nurse education today, 77: 77-82. https://doi.org/10.1016/j.nedt.2019.03.012

[19] Nguyen, H.T., Dawal, S.Z.M., Nukman, Y., Aoyama, H., Case, K. (2015). An integrated approach of fuzzy linguistic preference based AHP and fuzzy COPRAS for machine tool evaluation. PloS one, 10(9): e0133599. https://doi.org/10.1371/journal.pone.0133599

[20] Saaty, T.L. (1986). Axiomatic foundation of the analytic hierarchy process. Management science, 32(7): 841-855. https://doi.org/https://doi.org/10.1287/mnsc.32.7.841

\section{Authors}

Nan Xia is a male, born in October 1984 in Qufu, Shandong Province. He got his $\mathrm{PhD}$ degree in University Putra Malaysia, Malaysia. He is a lecturer of ideological and political education in department of social science of Chengde Medical University. Meantime, His research direction includes pedagogy and politics. He has published 6 papers and participated in many subjects. Email: flyforever2008@163.com

Yanan Yang is a female, born in February 1986 in Luanping, Hebei Province. She is currently a lecturer in department of social science of Chengde Medical University. She graduated from Yanbian University. Her research direction includes pedagogy and politics. She has published 4 papers and participated in many subjects.

Article submitted 2021-07-17. Resubmitted 2021-08-20. Final acceptance 2021-08-29. Final version published as submitted by the authors. 